\title{
Four centuries of suicide in opera
}

Saxby A Pridmore MB BS, MD, FRANZCP Professor of Psychiatry

Stephane Auchincloss MB BS, MRCP, FRANZCP Psychiatrist

Nerissa L Soh BMedSc, MNutrDiet, PhD Research Officer to the Chair of Child and Adolescent Psychiatry

Garry J Walter MB BS, PhD, FRANZCP Professor of Child an Adolescent Psychiatry,4

1 University of Tasmania Hobart, TAS

2 Hobart, TAS

3 Northern Sydney Local Health District, Sydney, NSW.

4 University of Sydney, Sydney, NSW.

garry.walter@ sydney.edu.au

MJA 2013; 199: 783-786 doi: 10.5694/mjal3.10724
For suicide is not simply a medical "problem", or even a public health "problem" - it is a complex cultural and moral concern that is deeply embedded in social and historical narratives and is unlikely to be greatly altered by any form of health intervention. $^{1}$

$\mathrm{n}$ the late 19th century, the founder of modern sociology, Émil Durkheim, showed that suicide rates differed between countries. ${ }^{2}$ He found that, in Europe and Scandinavia, the order for countries ranked from lowest to highest suicide rate was Italy, England, Norway, Sweden and France, and recent research has confirmed that this order has remained the same. ${ }^{3}$ The consistently different suicide rates of different countries suggests that culture influences these rates. The impact is presumably bidirectional - culture (in essence, the shared products of human society ${ }^{4}$ ) shapes our lives and, over time, our lives shape culture.

Opera is one of the many strands of aesthetic culture in human society. Monteverdi's L'Orfeo (Orpheus), which was debuted in 1607, is regarded as the first successful opera; about 30000 operas have been written subsequently, most never staged. ${ }^{5}$ Fortunately, the texts (libretti) of produced operas are available in print and amenable to examination. Thus, apart from having artistic appeal, operas are able to provide snapshots of librettists' ideas about emotions and reactions to adversity at particular times in history. It has been argued that opera, like other art forms, "reflects contemporary beliefs about interpersonal relationships and society". 6

With the task of entertaining an audience, which may involve a degree of exaggeration and the expectation that good will triumph over evil, the librettist generally strives to present a story which is plausible to the audience. To this extent, opera has the potential to offer a valid perspective of the attitudes toward suicide at specific times.

The topic of suicide in opera has received only modest interest in the

\section{Abstract}

Objective: To describe the depiction of completed suicide, non-fatal suicidal acts and suicidal thought in Western opera over the past four centuries.

Design and setting: Examination of synopses all of the operas listed in a recent monograph covering a selection of operas written in the period 1607-2006.

Main outcome measures: Frequency of completed suicides, non-fatal suicidal acts and suicidal thoughts over the entire 400-year period and in separate 100year periods (1607-1706, 1707-1806, 1807-1906 and 1907-2006);

circumstances of suicides; sex of the suicidal characters; and, for completed suicide, the method.

Results: There were 337 operas in total. In 112 (33\%), there was completed suicide alone, non-fatal suicidal acts or suicidal thoughts alone, or both. There was at least one suicide in 74 operas (22\%); female characters accounted for $56 \%$ of these. Non-fatal suicidal acts or suicidal thoughts were found in 48 operas (14\%); male characters accounted for $57 \%$ of these. Suicide, non-fatal acts and suicidal thoughts always followed an undesirable event or situation. Cutting or stabbing was the most common method of suicide (26 cases). Other methods included poisoning (15 cases), drowning (10 cases), hanging (four cases), asphyxiation (four cases), "supernatural" methods (four cases), immolation (three cases), jumping from a height (two cases), shooting (one) and blunt trauma (one). Mass suicide occurred on two occasions.

Conclusions: Over several centuries in opera, suicide has been frequently represented as an option when characters have been faced with a distressing event or situation. Historical fluctuations in the frequency of suicidal behaviour in opera may be explained by changes in attitudes towards suicide and its conceptualisation.

scientific literature. One qualitative study ${ }^{6}$ and one quantitative study ${ }^{7}$ are available, and these are both dated. The author of the qualitative study opined that, while suicide was common, "attempted suicides" were "missing from the operatic stage" ${ }^{6}$ The quantitative study, published in 1971, was cross-sectional and found that, in leading opera houses throughout the world, suicide featured in $26 \%$ of the different operas and in $40 \%$ of the most popular operas. ${ }^{7}$

Our aim in this study was to examine the depiction of completed suicide as well as non-fatal suicidal acts and suicidal thought in Western opera over the past four centuries, with a view to characterising such behaviour as conceived by librettists and received by the public, and as an indication (at least in part) of more widespread contemporaneous beliefs about suicide.

\section{Methods}

We examined all of the operas that debuted from 1607 to 2006, inclusive, that were listed in a popular opera guide published in 2007..$^{5}$ This guide provides a synopsis of each opera. If further details were required, we consulted comprehensive accounts. ${ }^{8-10}$ We considered the overall period 1607-2006 as well as separate 100year periods (1607-1706, 1707-1806, 1807-1906 and 1907-2006). We collected data on completed suicides, non-fatal suicidal acts and suicidal thoughts, and on the circumstances of these and whether there was evidence of an underlying mental disorder. We recorded the sex of the characters involved and, for completed suicide, the method.

Although our main focus was suicidal behaviour and thought, we also recorded other forms of violence (such as war, murder, rape and kidnap), and identified operas in which murder preceded suicide.

\section{Results}

We identified 337 operas in the period of interest. Over those 400 years, there was at least one suicide in 74 
1 Operas with completed suicide, non-fatal suicidal acts and suicidal thoughts, by 100 -year periods

Operas with

\begin{tabular}{lcccc} 
& & \multicolumn{4}{c}{ Operas with } \\
\cline { 3 - 5 } $\begin{array}{l}\text { Period } \\
\text { (calendar years) }\end{array}$ & $\begin{array}{c}\text { Number } \\
\text { of operas }\end{array}$ & $\begin{array}{c}\text { Completed } \\
\text { suicide }\end{array}$ & $\begin{array}{c}\text { Non-fatal } \\
\text { suicidal acts or } \\
\text { suicidal thoughts }\end{array}$ & $\begin{array}{c}\text { Completed suicide and/or } \\
\text { non-fatal suicidal acts and } \\
\text { suicidal thoughts }\end{array}$ \\
\hline $1607-1706$ & 13 & $3(23 \%)$ & $2(15 \%)$ & $5(38 \%)$ \\
$1707-1806$ & 42 & $4(10 \%)$ & $15(36 \%)$ & $17(40 \%)$ \\
$1807-1906$ & 141 & $40(28 \%)$ & $19(13 \%)$ & $55(39 \%)$ \\
$1907-2006$ & 141 & $27(19 \%)$ & $12(9 \%)$ & $35(25 \%)$ \\
Total & 337 & $74(22 \%)$ & $48(14 \%)$ & $112(33 \%)$
\end{tabular}

operas (22\%), mostly among female characters, who accounted for $56 \%$ of cases. Non-fatal suicidal acts or suicidal thoughts were found in 48 operas $(14 \%)$, predominantly among male characters cutting (including stabbing), who accounted for $57 \%$ of cases. In 112 operas (33\%), there was completed suicide and/or non-fatal suicidal acts and suicidal thoughts. The suicide-related events in operas in the separate 100-year periods, and overall, are shown in Box 1.

Cutting (including stabbing) was the most common method of suicide in opera (26 cases); this was the case for both male (15) and female (11) characters. Other methods included poisoning (15 cases; six male, nine female), drowning (10 cases; two male, eight female), hanging (four cases; two male, two female), asphyxiation (four cases; all female), "supernatural" methods (four cases; two male, two female), immolation (three cases; two male, one female), jumping from a height (two cases; both female), shooting (one male), blunt trauma (one male) and refusing lifesaving treatment (one female). Mass suicide occurred in two operas.

In 178 operas $(53 \%)$, there were other forms of violence - murder, rape, torture and arson were not infrequent events - and it was noteworthy that many operas were set during periods of war. Murder preceded suicide in 12 operas.

\section{Discussion}

Over the course of four centuries, a third of all of the operas we examined featured completed suicide, non-fatal suicidal acts or suicidal thoughts. Our finding that completed suicide was depicted in $22 \%$ of operas is consistent with rates of $25 \%{ }^{6}$ and $26 \%{ }^{7}$ reported in earlier studies. However, our finding that non-fatal suicidal acts or suicidal thoughts were represented in $14 \%$ of operas is in contrast to that of an earlier report that found no evidence of "attempted suicide" in opera. ${ }^{6}$ We

\section{Deborah Riedel as Juliette and Stephen Ibbotson as Roméo in Gounod's Roméo et Juliette}

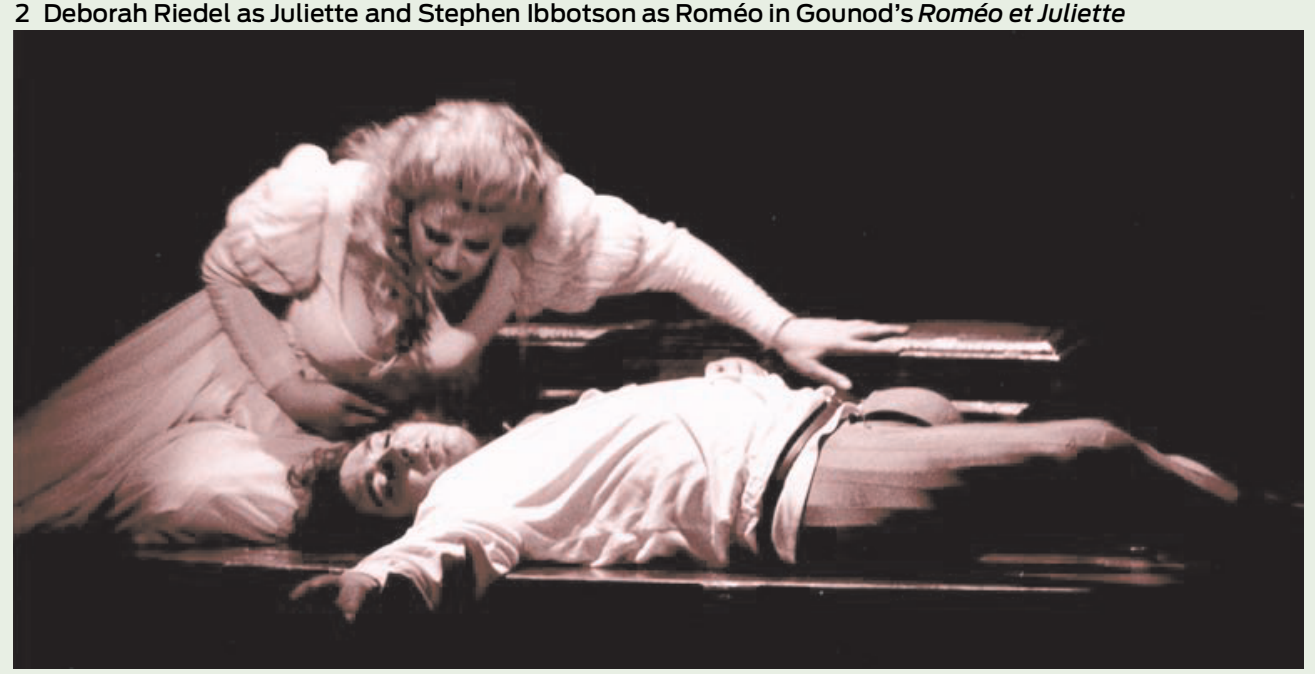

Libretto by Jules Barbier and Michel Carré

1992 Opera Australia production. Photo: Kiren Chang.

did not separate non-fatal suicidal acts from suicidal thoughts, but these appear to have been represented about equally, and we identified at least a modest number of non-fatal suicidal acts by characters in operas (examples include Atys in Lully's Atys, Idamante in Idomeneo, and Andronico in Handel's Tamerlano).

It is intriguing that cutting was the most common method of completed suicide for both male and female characters, as this is not the case in real life (notwithstanding possible differences in method over time, and according to culture). The World Health Organization mortality database suggests that, from the 1950s, shooting, hanging, jumping from a height and poisoning have been the most frequent methods, and that violent methods are more frequent among men than women. ${ }^{11}$ Although we can not be certain why cutting is the most common method in opera, presumably it has greater dramatic potential onstage, which would appeal to both the librettist and the audience.

It is also of interest that female characters accounted for most completed suicides in opera (56\%) and that non-fatal acts or thoughts were more common for male characters (57\%); both findings are a reversal of the sex differences encountered in real life. Again, we can only speculate about the reasons, but it is arguable that this may have been influenced by the librettist's and audience's sex role perceptions. Completed suicide may have been somehow more socially acceptable for women than men, for whom it may have represented a sign of weakness.

Importantly, without exception, the suicide or non-fatal suicidal acts or suicidal thoughts described in our opera sample immediately followed an undesirable event or situation, such as loss of a loved person, loss of position or authority or imminent submission to a dominant force, rather than occurring in the context of an underlying mental disorder (as much as one can recognise such disorders from libretti). Familiar examples include Romeo's suicide in Gounod's Roméo et Juliette (Box 2) and Cio-Cio-San's in Puccini's Madama Butterfly (Box 3). It is possible that the 
range of symptoms and signs satisfying criteria for a mental disorder are often too difficult for the librettist to accurately and persuasively depict. Nevertheless, the notion that suicide does not invariably occur in the setting of mental disorder has been articulated in previous publications. ${ }^{12,13}$ Our own group has developed the concept of "predicament suicide", in which we have delineated two major predicaments that may contribute to suicide. ${ }^{14,15}$ One predicament is untreated or unresponsive painful mental disorder and the other is an intolerable social situation. Completed suicide in opera appears to occur in response to predicaments in the latter category.

It is worth commenting briefly on the higher percentages of suicide and non-fatal suicidal acts and suicidal thoughts in the 18th and 19th centuries compared with the 20th and early 21st centuries. This finding could be attributed to changes in the attitude to suicide. In the early 18th century, suicide was considered a sin by the church and a crime under the law. Later that century, suicide shifted from a moral to a medical (mental illness) problem, and then came the "standard view" proposing that suicide was not always the result of mental disorder. ${ }^{11}$ The Romantic Movement favoured notions like suicide as an escape from a cruel world and a method of solving painful love problems. The new paradigm commenced about the time of publication of Goethe's Die Leiden des jungen Werther (The sorrows of young Werther) in $1774^{16}$ (which led to a large number of "copycat" suicides ${ }^{17}$ ) and the beginning of the French Revolution, and continued to the end of the 19th century. During the 20th century, suicide was strongly cast as a mental disorder rather than a reaction to a distressing event or situation., 1,3,18-20 This may have reduced librettists' use of suicide and related behaviour in operas over the past century.

Notwithstanding these historical fluctuations, what is clear is that over many centuries in Western and other cultures, suicide has been represented as an option when individuals have been faced with various forms of severe loss or other distressing situations. In our earlier work, we found numerous examples of suicide in response to stress, without apparent mental disorder, in the folk-stories of the ancient people of Greece ${ }^{21}$ and Germany and Finland, ${ }^{22}$ in satirical tales of 14th century Italy in Boccaccio's The Decameron, ${ }^{23}$ and in more recent literary fiction. ${ }^{24}$

It would be fascinating to ascertain whether suicide rates in opera have varied according to country, in much the same way that suicide rates in the real world vary in different countries. However, this would be very difficult because librettists and composers are mobile people - many are born in one country, settle in another and have their work set in or first performed in yet another. Our study is essentially of the "opera of Europe".

A limitation of our study is that only 337 operas were examined, and many thousands have been written. However, our sample was extracted, in toto, from a recent opera guide whose author, Matthew Boyden, set out to represent all eras of opera history, and "concentrated on the ones you're likeliest to encounter either on disc or on stage" 5

Well meaning colleagues and musicians offered us lists of operas in which completed suicide, attempted suicide or suicidal thinking featured, but as these would have introduced bias we put them aside and included only those operas mentioned in Boyden's text.

Apart from providing a glimpse into community beliefs about suicidal behaviours and data about changes in beliefs over time, our findings prompt speculation about the impact of opera depictions of suicide on real-world suicidal behaviour. There is ongoing debate about the influence of depictions of suicide in various media and the arts on subsequent copycat suicides. ${ }^{25}$ It may be too adventurous to suggest that the portrayal of suicide in opera will directly contribute to selfharming behaviour of members of the community on a large scale (let alone suggest that the drop in opera depictions of suicide in the 20th century was due to librettists' potentially heightened social responsibility). Although not lacking exposure - it is estimated that there will be over 24500 opera performances globally in the 2012-2013 season ${ }^{26}$ — opera is
3 Jennifer Barnes as Cio-Cio-San in Puccini's Madama Butterfly

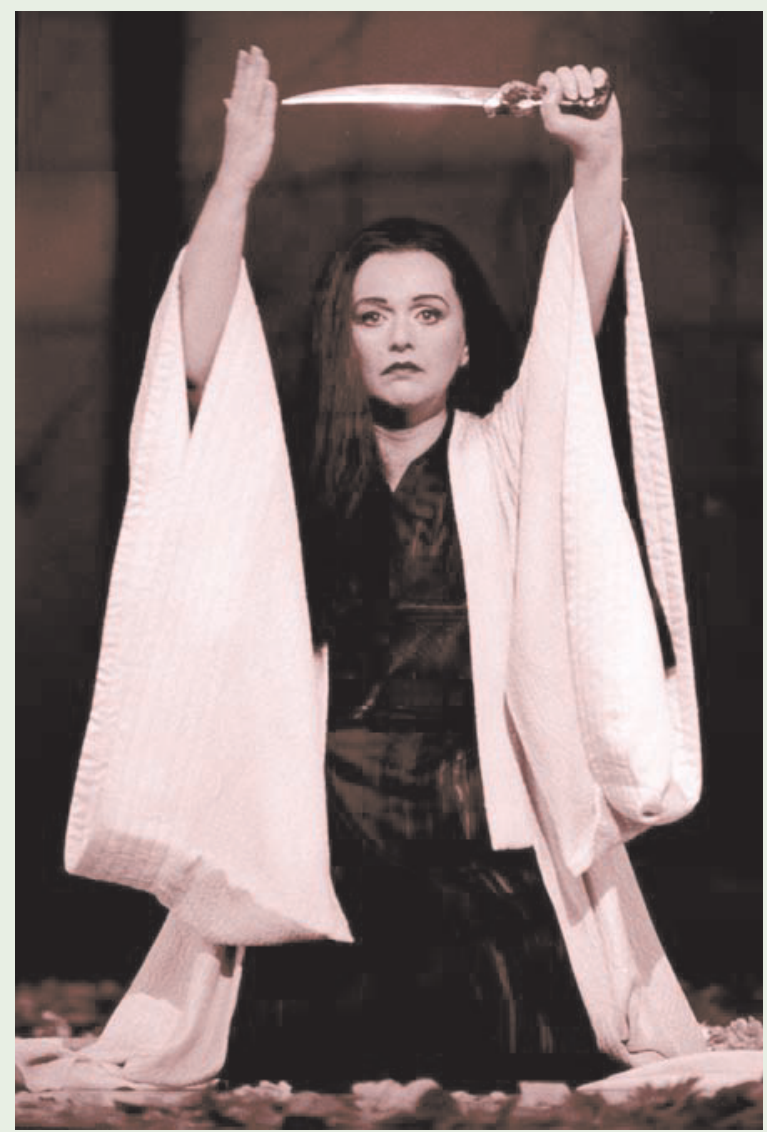

Libretto by Luigi Illica and Giuseppe Giacosa.

1999 Opera Australia production. Photo: Marco Bok.

4 Warwick Fyfe as Papageno in Mozart's Die Zauberflote (The magic flute)

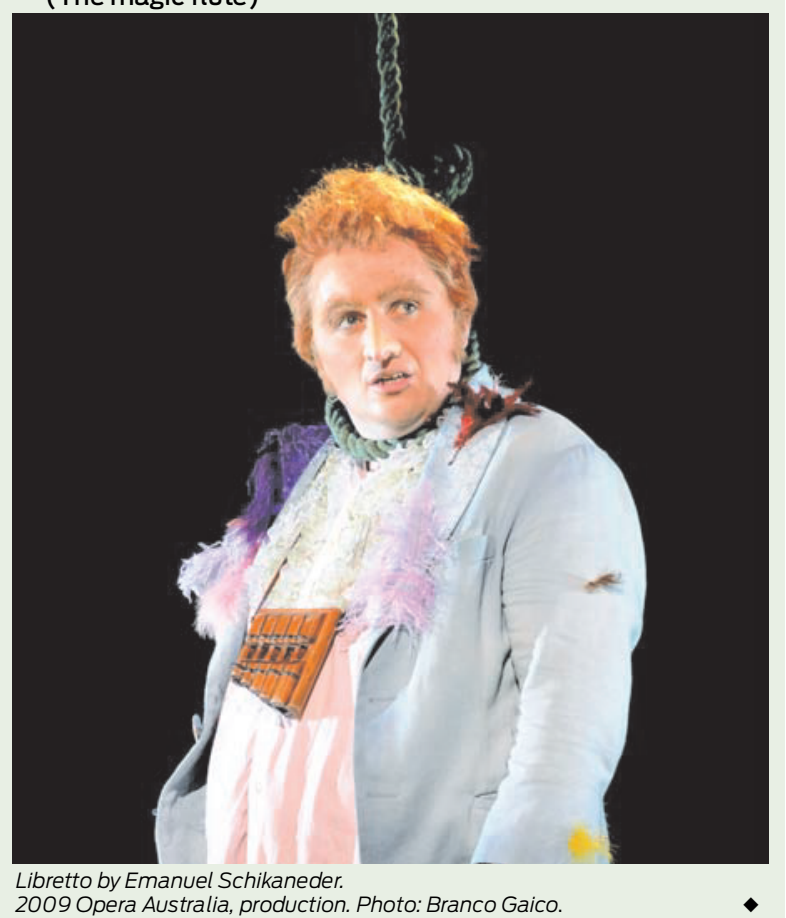


struggling to retain, let alone broaden its audience. ${ }^{27}$ Opera may not be as popular or potentially influential as, say, a blockbuster movie. Nevertheless, it is staggering to contemplate that a full third of operas written over a period of 400 years have featured completed suicide, non-fatal suicidal acts or suicidal thoughts. Might not these depictions affect the behaviour of a vulnerable member of the audience or a brittle person who can nowadays view opera in DVD and other formats? The "Papageno effect", denoting preventive suicide action, is worth mentioning here. This term was derived from Mozart's 1791 opera, Die Zauberflote (The magic flute), referring to a situation where Papageno, a young man in love, becomes suicidal on believing he has lost his love, but copes following his friends' intervention (Box 4). ${ }^{28}$

In conclusion, the representation of suicide in opera is too prominent to be ignored. While many opera buffs may focus on the musical elements rather than the action and libretti of this art form, the depiction of suicide in operatic works adds to our understanding of the cultural dimensions of suicide over time, and thus to our overall understanding of this tragic outcome.
Acknowledgements: We thank Opera Australia (OA) for permission to publish several photographs of OA productions, and Michael Pedersen, OA publications manager, for his assistance. We thank Branco Gaico for permission to publish the photograph of Papageno.

Competing interests: No relevant disclosures.

Received 3 Jun 2013, accepted 2 Oct 2013.

1 Fitzpatrick SJ, Kerridge IH. Challenges to a more open discussion of suicide. Med J Aust 2013; 198 470-471.

2 DurkheimÉ. Suicide: a study in sociology. Spaulding JA, Simpson G, translators. New York: The Free Press, 1951 [1897].

3 World Health Organization. Suicide rates per 100,000 by country, year and sex. WHO, 2011 http://www.who.int/mental_health/prevention/ suicide_rates/en/\# (accessed Jul 2013).

4 Robertson I. Sociology. 3rd ed. New York: Worth Publishers, 1987.

5 Boyden M. The rough guide to opera. London: Rough Guides, 2007.

6 Feggetter G. Suicide in opera. Br J Psychiatry 1980; 136: 552-557.

7 Walley KW, Kalish RA. Suicide in opera: a brie analysis. OMEGA - J Death Dying 1971; 2: 191-194.

8 Osborne C. The opera lover's companion. New Haven: Yale University Press, 2004.

9 Forman D. The good opera guide. London: Phoenix Press, 2001

10 Parker R, Abbate C. A history of opera: the last four hundred years. London: Allen Lane, 2012.

11 Ajdacic-Gross V, Weiss MG, Ring M, et al. Methods of suicide: international suicide patterns derived from the WHO mortality database. Bull World Health Organ 2008; 86: 726-732.

12 Berrios GE. The history of mental symptoms: descriptive psychopathology since the nineteenth century. Cambridge: Cambridge University Press, 1996.

13 Pilcz A. Contribution to the study of suicide. Ann Med Psychol (Paris) 1908; 7: 193-205.
14 Pridmore S. Predicament suicide: concept and evidence. Australas Psychiatry 2009; 17: 112-116.

15 Pridmore S. Suicide and predicament: life is a predicament. Bentham eBooks, 2010. http:// www.benthamscience.com/ebooks/ 9781608051694/index.htm (accessed May 2013).

16 Von Goethe JW. The sorrows of young Werther [German]. Leipzig: Weygand'scheBuchhandlung, 1774.

17 Phillips DP. The influence of suggestion on suicide: substantive and theoretical implications of the Werther Effect. Am Sociol Rev 1974; 39: 340-354.

18 Dorpat TL, Ripley HS. A study of suicide in the Seattle area. Compr Psychiatry 1960; 1: 349-359.

19 Jamison KR. Night falls fast: understanding suicide. New York: Vintage Books, 2000.

20 Bertolote JM, Fleischmann A, De Leo D, Wasserman D. Psychiatric diagnoses and suicide: revisiting the evidence. Crisis 2004; 25: 147-155.

21 Pridmore S, Majeed ZA. The suicides of The Metamorphoses. Australas Psychiatry 2011; 19: 22-24.

22 Pridmore S, Ahmadi J, Majeed ZA. Suicide in Old Norse and Finnish folk stories. Australas Psychiatry 2011; 19: 321-324.

23 Pridmore S, Walter G. Suicidal ideation and completed suicide in The Decameron. Turkish J Psychiatry, in press.

24 Pridmore S, Walter G. Does art imitate death? Depictions of suicide in fiction. Australas Psychiatry 2013; 21: 65-72.

25 Martin G. On suicide and subcultures [editorial]. AeJAMH 2006; 5: 166-170.

26 Operabase. Opera statistics 2012/2013. http:// operabase.com/top.cgi (accessed May 2013).

27 Terracini L. Re-imagining opera in Australia. Policy 2012; 28: 43-48.

28 Niederkrotenthaler T, Voracek M, Herberth A, et al. Role of media reports in completed and prevented suicide: Werther v. Papageno effects. Br J Psychiatry 2010; 197: 234-243. 